\title{
PROBLEMS OF PARENTS CARING FOR CHILDREN WITH DISABILITIES
}

\author{
Maryna Lekholetova \\ Borys Grinchenko Kyiv University, Ukraine \\ Tetiana Liakh \\ Borys Grinchenko Kyiv University, Ukraine \\ Nataliia Zaveryko \\ Zaporizhzhia National University, Ukraine
}

\begin{abstract}
The development of integrated social services for parents raising children with disabilities is one of the priorities of social policy in Ukraine.

The purpose of this article is to identify the typical problems of parents raising children with disabilities. Based on the in-depth interviews conducted by parents raising children with disabilities in two regions of Ukraine $(n=60)$, groups of typical problems they face (discrimination, medical problems, imperfection of regulatory support, information problems, access problems, problems of early diagnosis / early intervention, psychological problems, risk of institutionalization, financial and economic problems) and their analysis. In-depth interviews identified issues that could provide brief guidance on social work with families raising children with disabilities.

The authors draw attention to the urgent and structural changes needed to improve the access of parents of children with disabilities to quality social services and to improve the quality of their social and pedagogical support, including enhancing the educational potential of such parents.
\end{abstract}

Keywords: family; children with disabilities; family problems; risk factors for child developmental disorders; social work with families; early intervention.

\section{Introduction}

In Ukraine, a state system of social support for persons with disabilities was formed, however, it focuses mainly on compensation and makes a person with a disability dependent on the help of others. The situation is even more complicated when it comes to children with disabilities. At this stage, the main socializing function is provided by the closest environment of a person - his or her family. The process of adaptation of the child in society and his or her inclusion in the educational environment, observance of rights and freedoms guaranteed by the Constitution of Ukraine largely depend on the parents or their substitute. 
The reform of decentralization and deinstitutionalization will be completed in Ukraine by the end of 2020. Local communities can independently form the structure of social agencies and determine the list of social services. The functioning of the boarding school system is being terminated in the country. Thus, now children with different nosologies would be looked after by local communities, favoring family-based care. Unfortunately, the country does not have a high percentage of adopting children and adopting them into foster and patronage families. Therefore, it can be predicted that the situation of children with disabilities can become threatening and such children can become "unnecessary" in the community. The country would once again return to the segregated model of social work with disabled people.

The core task of the social worker is to understand the typical problems of families caring for children with disabilities, to provide further empowerment and development of parental educational competence of such a child, to promote development of independence of this group of people, to develop the ability to identify their own resources and community resources to solve problems emerging in front of such person or family.

Therefore, searching the problems of families caring for children with disabilities is extremely relevant and can help social workers to advocate for the interests of such families in order to provide them with high-quality social and social-pedagogical support.

\section{Literature review}

Numerous studies are dedicated to the problems of families caring for children with disabilities; the issue is of scientific interest to many researchers. For the most part, scientists have focused on two aspects: the impact of a child with a disability on family functioning and the impact of the family on the future of a child. These studies have changed the paradigm of services for children with disabilities; thereby not only a child with a disability but the entire family has become the object of social work (McDonald, 1971). The transition from a biomedical model to a family-centered one has been driven by the realization that a disability of a child is a great stress and a serious challenge for the family. It causes strong emotional reactions of all family members (shock, denial, fear and anxiety, realistic adaptation) (Kubler-Ross (1969), Blasher (1984), and changes relationships.

Social and pedagogical support for a child and his or her family was researched by Ukrainian scientist T. Alieksieienko (Alieksieienko, 2016).

The group of authors (Guralnick, Hammond, Neville, \& Connor, 2008) of the book «Understanding Families: Supportive Approaches to Diversity, Disability, and Risk» focuses on the importance of ensuring family resilience, and 
therefore it is necessary to form preservice and in-service readiness of professionals to work with a broad range of families with diverse structures, backgrounds, and circumstances, to communicate and collaborate effectively with every family they serve, to support families of children with disabilities, to empower strong parent-child relationship and interactions, to coordinate services and support with goals of each family and to address risk factors such as poverty, addiction, and violence.

J. Matejek (Matejek, 2019) in his article "A family with many problems in the social support system" emphasizes the importance of building a broad system of social support for families in difficult circumstances. These families include families who care for children with disabilities according to the scientist.

The study by a group of authors (Kochetkov et al., 2018) is important to understand the implications of parental support for children with disabilities It has been grounded that psychological and pedagogical support at the stage of a child's entry into the inclusive educational environment must be directed towards the search for the internal resources of parents or caregivers of children with special needs for the purpose of harmonizing and improving their psychical state, raising the level of their resilience, and ability to overcome difficulties by means of building up personal resources. It has been proved that modern psychological support for parents under conditions of inclusive education will help to neutralize and reduce the extent of emotional stress expressiveness which will consequently lead to the child's disability acceptance and hence, it will provide his or her further integration into society.

Most researchers include families living with children with disabilities to vulnerable categories, emphasizing that under the influence of negative factors such a family can easily switch from "vulnerable" to a different status - "family in difficult circumstances". Moreover, it is essential to understand the typical problems of such families in order to prevent difficult life circumstances through early intervention by a social worker.

\section{Methodology}

In the period from November 2018 to May 2019, we conducted in-depth interviews with 60 family members raising children with disabilities in Kyiv and Zaporizhzhya regions of Ukraine. The purpose of the in-depth interviews was to identify the typical problems of these families, to analyze them, to provide advice to social care professionals on the social support of families raising children with disabilities depending on the problem identified.

The sampling of respondents was shaped by the "snowball" method through social media, websites of NGOs and social services, as well as through personal letters to family members raising children with disabilities. The sampling was 
based on the gender of parents, age, education, presence of a child with a disability, marital status. Data encoding went in parallel with the fieldwork, which guided the sampling strategy according to emerging topics. We invited only one adult family member for an interview.

The data were collected through in-depth interviews conducted with a thematic guide. Interviews were conducted by trained interviewers. The interviews were freely structured. Interviews were recorded on audio media with the informed consent of the participants and lasted from 30 to 90 minutes. All interviews were conducted outside social services and community-based organizations providing services to families raising children with disabilities.

The interviews were transcribed verbatim, translated into English. Preliminary coding was conducted to determine the descriptive topics, which was subsequently refined and interpreted using MaxQDA10.

The interviewed topics included: risk factors for child developmental disorders; typical problems, difficulties of families caring for children with disabilities; suggestions from family members caring for children with disabilities how to provide them with social support.

The interview questions were conditionally grouped into three blocks:

1) characteristics of families caring for children with disabilities;

2) the impact of disability on the family functioning and the impact on a child;

3) providing social support for families living with disabled children.

\section{Research results}

The in-depth interviews were conducted with 60 family members caring for children with disabilities in two regions of Ukraine: Zaporizhzhia and Kyiv regions. The first stage of the interviews was gathering information about respondents.

Table 1 Information about respondents

\begin{tabular}{|l|l|}
\hline \multicolumn{2}{|c|}{$\mathrm{n}=60$} \\
\hline \multirow{4}{*}{ Age range (\%) } & From 20 to 30-14(23,33\%) \\
\cline { 2 - 2 } & From 31 to 40-18 (30\%) \\
\cline { 2 - 2 } & From 41 to 50-16(26,66\%) \\
\cline { 2 - 2 } & From 51 to 60 - 12 (20\%) \\
\hline \multirow{3}{*}{ Education (\%) } & Secondary education - 14 (23,33\%) \\
\cline { 2 - 2 } & Vocational and technical education - 18 (30\%) \\
\cline { 2 - 2 } & High education - 28 (46,66\%) \\
\hline \multirow{2}{*}{ Gender (\%) } & Male - 13 (21,66\%) \\
\cline { 2 - 2 } & Female - 47 (78,33\%) \\
\hline \multirow{2}{*}{ Marital status (\%) } & Married - 32 (53,33\%) \\
\cline { 2 - 2 } & Single - 28 (46,66\%) \\
\hline
\end{tabular}


SOCIETY. INTEGRATION. EDUCATION

Proceedings of the International Scientific Conference. Volume IV, May $22^{\text {th }}-23^{\text {th }}, 2020.268-278$

\begin{tabular}{|c|l|c|}
\hline \multicolumn{3}{|l|}{ Type of disability of the child: } \\
\hline $\begin{array}{l}\text { - physical } \\
\text { disability }\end{array}$ & $\begin{array}{l}\text { physiological, functional and/or mobility impairments, } \\
\text { disorders of the musculoskeletal system, diseases of the } \\
\text { central nervous system, diseases of the muscular system, } \\
\text { diseases of the joints, diseases of the vessels, somatic } \\
\text { diseases, diseases of the internal organs, blood diseases }\end{array}$ & $28,66 \%)$ \\
\hline $\begin{array}{l}\text { - sensory } \\
\text { disability }\end{array}$ & disability of the senses & $10(16,66 \%)$ \\
\hline $\begin{array}{l}\text { - intellectual } \\
\text { (cognitive) } \\
\text { disability }\end{array}$ & mental retardation & $14(23,33 \%)$ \\
\hline- mental disability & $\begin{array}{l}\text { mental illness, emotional and volitional disorders, } \\
\text { epilepsy, autism, Down syndrome }\end{array}$ & $8(13,33 \%)$ \\
\hline
\end{tabular}

The results of the interviews show that the vulnerability of families caring for children with disabilities, in addition to disabilities of these children is also exacerbated by socio-psychological factors (Fig. 1). Thus, 26 people (43.33\%) suffer from systematic discrimination, 10 persons (16.66\%) do not have access to information and communication, 32 people (53.33\%) report obstacles in obtaining the necessary health care and rehabilitation services, 14 people (23.33\%) complain about educational opportunities that are not equal to other (limited access to regular schools and higher education institutions), 28 people (46,6\%) claim architectural inaccessibility of housing, transport and infrastructure.

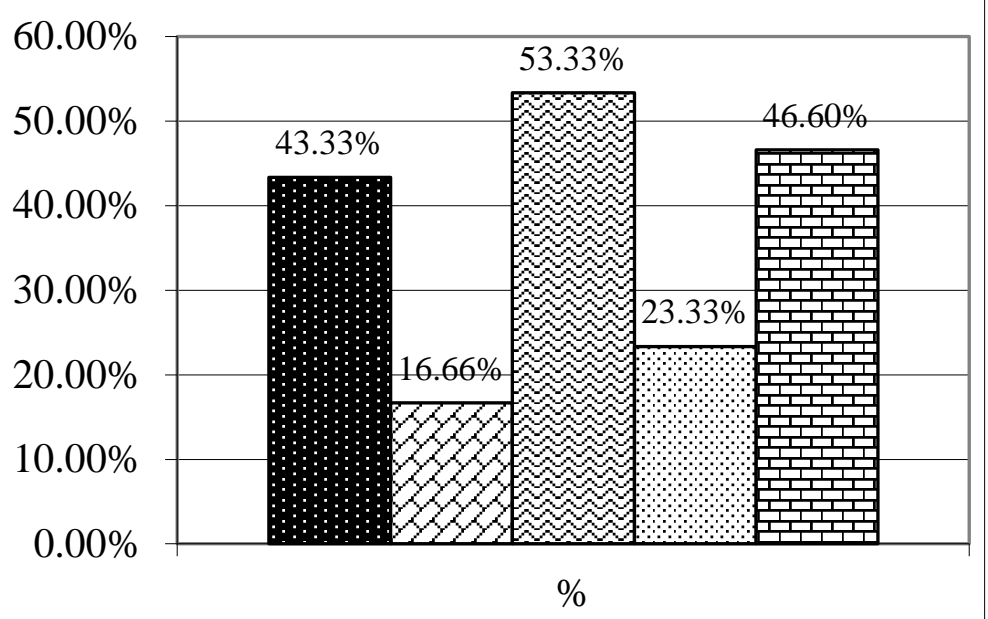

Systematic discrimination

[ Lack of access to information and communication

๑Difficulty in obtaining services in health care and rehabilitation

๑Unequal educational opportunities

$\boldsymbol{\nabla}$ Architectural inaccessibility of housing, transport and infrastructure

\section{Figure 1 Socio-psychological factors of vulnerability of families caring for children with disabilities}

According to the data above, we can conclude that the unmet needs of people with disabilities in rehabilitation (including the need for rehabilitation equipment) 
can lead to a deterioration in health status, restrictions on activities and participation in social life, and thus impair their quality of life.

Next, we searched to find out how a disability affects family functioning and a child.

It was found that $100 \%$ of respondents believe that the birth of a disabled child puts some limitations on normal family functioning. These are changes in the organization of life (13 people; $21.66 \%$ ), the need for redistribution of responsibilities (8 people; 13.33\%), giving up certain habits (18 people; 30\%), feeling of fear, uncertainty, helplessness (21 people; 35\%).

Therefore, to build a constructive dialogue with parents in determining the overall strategy of social support, to secure partnership to achieve these objectives, the social worker should take into account the stages of emotional experiences of parents when they learn that their child has developmental problems: shock, denial, fear, and anxiety, activity (Fig. 2).

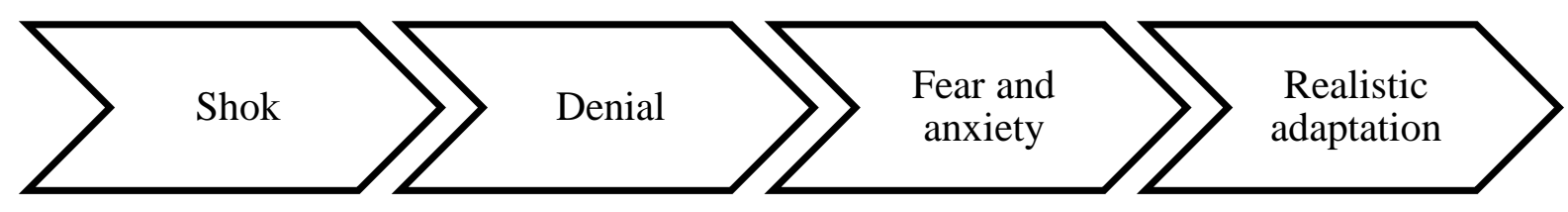

Figure 2 Stages of emotional experiences of parents raising children with disabilities

The stage of shock is usually accompanied by crying, screaming, or emotional numbness, and emotionlessness. At this stage, the family needs attention and support of the relatives. Therefore, it is impossible for social workers to talk to the parents about the perspectives at this stage. It's necessary to give them time and to focus on talking with their relatives about the importance of support.

The second stage is denial and it is important for social workers to understand the natural reaction of parents and the protective function of the denial. The denials hide the feelings of pain and despair that parents are not ready to handle. The social worker should be very patient and tactful, and most importantly - not intrusive. Loneliness, fatigue from the constant and unsuccessful search for ways to heal a child, exhausting caring for a child, and giving up all their own needs and interests - all this leads to depression. Therefore, parents need qualified psychological assistance.

Social workers should be focused on supporting parents to be good and loving. This is accomplished through the comments in moments of positive interaction between parents and child, recognizing the importance of parental love for a child, as well as through consulting parents on understanding the age characteristics and needs of a child and their role as parents in the education, formation of self-reliance, self-esteem and further socialization. 
The stage of fear and anxiety is characterized by emotional relief, objective perception of the reality of the problem of a child. Therefore there is anxiety about the future of a child (development, learning). At this stage, it is important to provide parents with full information about the problem so that they can make informed decisions and act in the best interests of their child, to understand the distinction between limitations and opportunities, to accept the reality of something that cannot be changed, and know what can be achieved.

The stage of realistic adaptation and seeking help is a good moment in establishing partnerships with parents since parents are re-evaluating values, which stimulates activity. Social workers should focus on helping them to find the services they need, keeping in touch with the family.

In order to define the required type of social support for a particular family caring for a child with a disability, it is necessary to identify the groups of typical problems for this category of families.

During the interview, we have identified that one of the pressing problems for families caring for children with disabilities is low financial resources (financial inaccessibility of improving living conditions, lack of funds to buy the necessary food, medicines, technical means of disability compensations). It was stated by 42 respondents (70\%). Most of these families live poorly. As single mothers caring for a child with a disability point out: "The situation was exacerbated by divorce in the first years after the birth. It was impossible to work because the baby needed constant care".

The birth of a disabled child can have profound effects on the well-being and psychological health of the entire family. Usually, there is a low level of psychological acceptance of the disabled child in the family, emotional rejection of a child. 29 (48.33\%) respondents mentioned the problems of psychological acceptance.

The parents of one child with a disability said that "... it was difficult to psychologically accept the situation. There was a lack of understanding of the social environment. For a long time, we are accompanied by a feeling of abandonment and loneliness".

The study pointed out that most families (48 people; $80 \%$ ) caring for children with disabilities need periodic health monitoring, improvement and rehabilitation. Respondents (52 persons; 86.66\%) indicated that today the technologies of early diagnostics, correction and prediction of medical consequences of disability are insufficiently developed and mostly unavailable.

As parents remarked "...there is a low level of free medical services and medicines provision in the country. And there are not enough qualified specialists". Thus, the absence of an early intervention system in Ukraine complicates work with a family caring for a child with a disability. 
The early identification of biological and social risk factors for child developmental disorders gives an opportunity to start intensive rehabilitation at an early age timely when child development is particularly impacted and can prevent complications of both family functioning and physical and psychological child development.

In the study, we found that health professionals often advise leaving the child with a disability. 32 (53.33\%) parents received this suggestion.

For example, one of the mothers told: "After the birth, a medical worker of the facility advised to leave my child for the maintenance of state institution. She said that a terrible life was ahead of me. I refused and took my baby home."

But there are frequent cases when being under stress, experiencing fear, helplessness in this situation, parents decide to leave the baby. This choice adversely affects not only the further development of a child but also leads to the destruction of marital relations in the future.

Lack of a well-established system of early intervention and responding to the situation on the benefit of the family and a child, setting up the system of institutional care for children are the pressing problems of families with children with disabilities. Developing a mechanism for providing the necessary early assistance to parents and children would prevent institutionalization and strengthen the family relationship.

Therefore, one of the main areas of work for social workers in the community should become services aimed at preventing the separation of a disabled child with the family.

The survey found that the majority of parents (42 people; 70\%) who care for children with disabilities have a lack of information about the characteristics of a child, the possibilities of correction and treatment, their rights to social assistance, benefits, relevant educational institutions, available state institutions, and nongovernmental organizations.

For example, the parents of one child with a disability, when asked, "Where did you learn about your rights and opportunities as the family caring for a child with a disability?" answered that they learned that information from friends who have the same problem in the family. They did not know how to apply for social, legal and psychological assistance because health workers do not have full information about social protection and support of such families and are not obliged to provide it.

The findings of the study give us reason to claim that on the state and local levels the public is not sufficiently informed about the types of social support the families with children with disabilities are entitled to. Parents (60 people; 100\%) reported the lack of information from the first days after the birth of their child. There is no specific procedure for informing the parents of a child born with a 
disability or disorder about their rights and opportunities to receive assistance from the state and public organizations at the stage of diagnosis.

About half of the respondents (28 people, 46.66\%) indicated that they often face prejudice and stereotypical attitudes towards them by many people. The situation is complicated by the psychological and moral overload of parents, their expressed anxiety and worries caused by the disability of their child, failure to adequately confront misunderstanding and even hostility from others. Often the circle of communication for such families is close relatives and professionals.

Along with the problem of not accepting people with disabilities as full members of society, there is a problem of inaccessibility of objects, buildings, transport problems and limited access to information. 100\% of respondents pointed it out.

The Convention on the Rights of the Child has been ratified and changes have been made to national legislation in accordance with international agreements to protect the rights of persons with disabilities. However, there are often contradictions between the rule of law and the state-governmental enforcement of these norms.

When asked "Who can be the service provider for the family that caring for a child with a disability and for a child?", respondents mostly answered that NGOs play a substantial role in this respect.

Ukraine has formed the state system of social support for persons with disabilities, but it is mainly focused on compensation and makes people with disabilities dependent on the help of others.

The objective of a social worker is to promote the development of autonomy of this group, to develop the ability to determine their own resources and community resources to address the family and personal problems.

\section{Conclusions and recommendations}

The study provided us with a good source of information to identify the groups of typical problems of families caring for children with disabilities (Fig. 3).

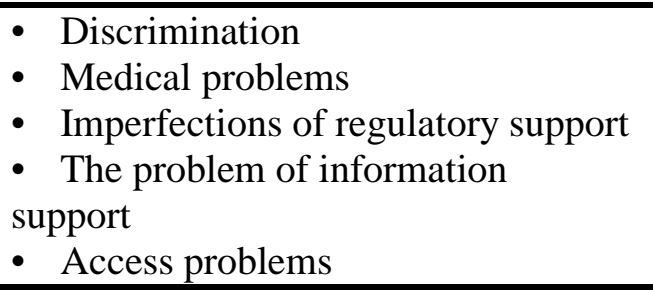

Figure 3 Groups of typical problems of families caring for children with disabilities 
We will explain the content of each of the issues.

1. Discrimination (non-acceptance of people with disabilities by members of society, bias and stereotyping).

2. Medical problems (a complex of problems related to treatment, correction and development of compensatory functions, obtaining technical means, meeting the needs for periodic health control, qualified consultations, and others).

3. Imperfections of regulatory support (contradictions between the norms of the law and the state-administrative support for the implementation of these norms).

4. The problem of information support (about the child characteristics, the possibilities of correction and treatment, the features of education, the rights to social assistance, etc.).

5. Access problems (problems with transportation and access to information).

6. Problems of early diagnosis / early intervention (insufficient development and inaccessibility of early diagnosis technologies, the absence of an early intervention system in Ukraine that complicates work with the family caring for a child with a disability).

7. Psychological problems (constant mental and nervous overload, misunderstanding of the social environment, emotional rejection of a child and other).

8. The risk of institutionalization (institutional child care).

9. Financial and economic problems (low income, difficulties in the realization of guaranteed benefits).

Social workers of Ukraine challenged to solve the above-mentioned problems, to prevent institutional care for children, and to provide social and pedagogical support for parents of children with disabilities.

Thus, the study shows that social support for families caring for children with disabilities is a pressing problem today. Therefore, an effective social support program for such families should be developed. The program should be based on the identified risk factors for child developmental disorders and take into account the problems of families caring for children with disabilities to prepare highly qualified specialists who will be able to provide legal, psychological, social and socio-pedagogical support.

\section{Acknowledgments}

The study was conducted in the framework of the scientific themes of the Institute of human Kyiv University named after Boris Grinchenko "Personality in 
SOCIETY. INTEGRATION. EDUCATION

Proceedings of the International Scientific Conference. Volume IV, May $22^{\text {th }}-23^{\text {th }}, 2020.268-278$

conditions of social transformations of modern Ukraine", registration number: 0116U002960, deadline - 5.2016-5.2021.

\section{References}

Alieksieienko, T. (2016). Social and pedagogical support for a child and his family: theoretical and methodological aspect of the professional training of specialists. Vocational Training Some Problems And Contexts: monography. (219-239). Chelm: Panstwowa Wizsza Szkola Zawodowa w Chelme. Chelmsckie Towarzstwo Naukowe.

Blasher, J. (1984). Sequential stages of parental adjustment to the birth of a child with handicaps: fact or artifact? Mental retardation, 22, 55-68

Glaser, B.G., \& Strauss, A.L. (2012). The Discovery of Grounded Theory: Strategies for Qualitative Research. New Brunswick \& London. Aldine Transaction.

Guralnick, M.J., Hammond, M.A., Neville, B., \& Connor, R.T. (2008). The relationship between sources and functions of social support and dimensions of child- and parentrelated stress. Journal of Intellectual Disability Research, 52, 1138-1154. DOI: https://doi.org/10.1111/j.1365-2788.2008.01073.x

Hanson, M.J., Lynch, E.W., \& Poulsen, M.K. (Collaborator). (2013). Understanding families: Supportive approaches to diversity, disability, and risk (2nd ed.). Paul $\mathrm{H}$ Brookes Publishing.

Kochetkov, I.G., Lopatkova, I.V., Mikhaylovsky, M.N., Mizonova, O.V., Carroll, V.V., \& Tarasenko, N.N. (2018). Specific Features And Principles Of Psychological And Pedagogical Support For Parents Bringing Up Children With Limited Abilities Under Conditions Of The Inclusive Education Implementation. Modern Journal of Language Teaching Methods, 8(1), 182-187.

Kubler-Ross, E. (1969). On death and dying. New York. The Macmillan Company.

Matejek, J. (2019). A family with many problems in the social support system. Society, Integration, Education, Vol. III, 271-281. DOI: http://dx.doi.org/10.17770/ sie2019vol3.3715

McDonald, E. (1971). Understand those feelings. Pittsburg: Stanwix House Inc. 